\title{
Effect of Avocado Soybean Unsaponifiables on Insulin Secretion and Insulin Sensitivity in Patients with Obesity
}

\author{
Esperanza Martínez-Abundis a, ${ }^{a} \quad$ Manuel González-Ortiz ${ }^{a}$ b \\ Arieh R. Mercado-Sesma ${ }^{b}$ Claudia Reynoso-von-Drateln ${ }^{a}$ \\ Aureliano Moreno-Andrade ${ }^{a}$ \\ ${ }^{a}$ Medical Research Unit in Clinical Epidemiology, Specialties Hospital, Medical Unit \\ of High Specialty, West National Medical Center, Mexican Institute of Social Security, \\ ${ }^{b}$ Cardiovascular Research Unit, Physiology Department, Health Science University Center, \\ University of Guadalajara, Guadalajara, Mexico
}

\section{Key Words}

Avocado soybean unsaponifiables · Insulin secretion · Insulin sensitivity · Obesity

\begin{abstract}
Aim: To evaluate the effect of avocado soybean unsaponifiables (ASU) on insulin secretion and insulin sensitivity in patients with obesity. Methods: A randomized, double-blind, placebo-controlled, clinical trial was carried out in 14 obese adult volunteers. After random allocation of the intervention, 7 patients received $300 \mathrm{mg}$ of ASU or placebo during a fasting state for 3 months. A metabolic profile including IL-6 and high-sensitivity C-reactive protein (hsCRP) levels was carried out prior to the intervention. A hyperglycemic-hyperinsulinemic clamp technique was used to assess insulin secretion and insulin sensitivity phases. Mann-Whitney $\mathrm{U}$ test and Wilcoxon test were performed for statistical analyses. The study was approved by the local ethics committee of our institution. Results: At baseline, both groups were similar according to clinical and laboratory characteristics. There was no significant difference in insulin secretion and insulin sensitivity with ASU. Conclusions: ASU administration for 3 months did not modify insulin secretion and insulin sensitivity in patients with obesity.
\end{abstract}

(c) 2013 S. Karger GmbH, Freiburg

\section{Introduction}

Obesity is a risk factor for the development of type 2 diabetes mellitus and cardiovascular disease [1,2]. Obesity is considered a low-grade chronic inflammatory state [3-5] and is frequently associated with insulin resistance and abnormalities in insulin secretion $[6,7]$. 
IL-6 and C-reactive protein (CRP) are involved in decreasing insulin secretion and insulin sensitivity $[8,9]$.

Avocado soybean unsaponifiables (ASU) are composed of fractions of one third avocado and two thirds soybean oils. They have shown to inhibit IL-1 $\beta$, IL-6, IL-8, TNF- $\alpha$, and prostaglandin $E_{2}$ due to unknown mechanisms $[10,11]$. Therefore, if ASU are prescribed for patients with obesity, they may decrease IL- 6 and CRP, increasing insulin secretion and probably insulin action.

The aim of this study was to assess the effect of ASU on insulin secretion and insulin sensitivity in patients with obesity.

\section{Subjects and Methods}

A randomized, double-blind, placebo controlled clinical trial was carried out in 14 obese (BMI 30-39.9 $\mathrm{kg} / \mathrm{m}^{2}$ ) adults (30-40 years of age) and volunteers with similar demographic and socioeconomic characteristics. All individuals were nonsmokers. Subjects' weight had remained stable for at least 3 months prior to the study. Blood pressure was $<130 / 80 \mathrm{~mm}$ Hg. Patients specifically denied the presence of rheumatic, renal, and metabolic diseases such as type 2 diabetes mellitus, dyslipidemia, hyperuricemia, and hypertension. None had used any other medications known to affect metabolism or any anti-inflammatory drugs, and all patients denied allergy to avocado or soybean. None of the subjects was pregnant or breastfeeding. An exclusion criterion was considered as compliance $<80 \%$ and was evaluated by counting capsules every month.

After random allocation of the intervention, 7 patients each received $300 \mathrm{mg}$ of ASU (Piascledine 300, Expanscience Lab., Courbevoie, France) or placebo orally during a fasting state for 3 months. All patients received general recommendations about their medical nutritional therapy and were instructed to not modify their usual exercise habits.

Before testing, an isocaloric diet of at least $250 \mathrm{~g}$ of carbohydrates/day was given for 3 days. Women were in the first phase of their menstrual cycle (3-8 days). Testing was initiated at 8:00 a.m. after a 12-hour fast. Height and weight were measured wearing shoes. Values were used to calculate BMI according to the formula: weight $(\mathrm{kg}) /$ height $\left(\mathrm{m}^{2}\right)$. Waist circumference was taken at the middle between the highest point of the iliac crest and the lowest rib in the mid-axillary line. Adiposity (\% of fat mass) was assessed by bioelectrical impedance analysis using a contact electrode foot-to-foot body fat analyzer system (TBF-300A, Tanita Corporation of America, Arlington Heights, IL, USA).

Venous blood was obtained with the subject supine in a quiet room. Blood was allowed to clot for 30 $\mathrm{min}$ at room temperature and then centrifuged. The resulting serum was placed into two aliquots: the first was used for determination of glucose, total cholesterol (TC), high-density lipoprotein cholesterol (HDL-C) and triglycerides (TG), and the second was frozen at $-20^{\circ} \mathrm{C}$ for measurement of IL- 6 and high-sensitivity CRP (hs-CRP) within the following 30 days. A hyperglycemic-hyperinsulinemic clamp technique was performed to assess the phases of insulin secretion and insulin sensitivity [12]. Briefly, two venous accesses were installed: the first one retrograde over some of the hand veins through a 19-gauge butterfly catheter for taking samples during the test. The hand was wrapped in a thermal pillow to achieve a local temperature $>40{ }^{\circ} \mathrm{C}$ to arterialize the blood. The second access was installed on the contralateral arm with a 19-gauge catheter. A $20 \%$ dextrose infusion was initiated: a priming dose for 14 min equivalent to $240 \mathrm{mg} / \mathrm{kg}$ body weight followed by a maintenance dose based on body weight, basal glucose, and the glucose required throughout the test ( $6.9 \mathrm{mmol} / \mathrm{l}$ higher than basal value). At 2, 4, 6, 8, and $10 \mathrm{~min}, 5 \mathrm{ml}$ of blood was taken and, after that, every $10 \mathrm{~min}$ for the next $120 \mathrm{~min}$ for insulin determination. At 5-min intervals, we took an additional $1.5-\mathrm{ml}$ blood sample for glucose determination to calculate the estimate of glucose metabolism and to be able to adjust the rate of dextrose infusion. At the end of the test (120 min), dextrose infusion was maintained for $30 \mathrm{~min}$ as a precaution to avoid hypoglycemia. With the above-mentioned results and using a calculator program, first (0-10 $\mathrm{min})$ and late $(10-120 \mathrm{~min})$ phases of insulin secretion as well as total insulin concentration (0-120 min) were calculated, and total glucose metabolism was used to evaluate insulin sensitivity.

Glucose concentration was measured using the glucose-oxidase technique (Ortho-Clinical Diagnostics, Rochester, NY, USA) with an intra- and inter-assay coefficient of variation $<1 \%$. TC, HDL-C, and TG were measured enzymatically. In particular, HDL-C was assessed after selective precipitation of non-HDL-C frac- 
Martínez-Abundis et al.: Effect of Avocado Soybean Unsaponifiables on Insulin Secretion and Insulin Sensitivity in Patients with Obesity

Table 1. Laboratory measurements at baseline and after pharmacological intervention

\begin{tabular}{|c|c|c|c|c|}
\hline & \multicolumn{2}{|l|}{ Placebo } & \multicolumn{2}{|l|}{ ASU } \\
\hline & basal & final & basal & final \\
\hline Weight, kg & $90.4 \pm 11.4$ & $89 \pm 9.9$ & $93.1 \pm 7.9$ & $93.3 \pm 7.9$ \\
\hline BMI, $\mathrm{kg} / \mathrm{m}^{2}$ & $34.5 \pm 3.5$ & $33.8 \pm 2.8$ & $35.6 \pm 2.8$ & $35.2 \pm 2.8$ \\
\hline $\mathrm{WC}, \mathrm{cm}$ & $112 \pm 8$ & $105 \pm 11$ & $110 \pm 5$ & $111 \pm 5$ \\
\hline Fasting glucose, mmol/l & $4.7 \pm 0.6$ & $4.6 \pm 0.4$ & $4.8 \pm 0.1$ & $4.7 \pm 0.4$ \\
\hline $\mathrm{TC}, \mathrm{mmol} / \mathrm{l}$ & $5.0 \pm 0.8$ & $5.2 \pm 0.6$ & $3.0 \pm 0.9$ & $4.7 \pm 0.7$ \\
\hline HDL-C, mmol/l & $1.1 \pm 0.2$ & $1.1 \pm 0.2$ & $1.1 \pm 0.3$ & $1.2 \pm 0.3$ \\
\hline LDL-C, mmol/l & $2.9 \pm 0.6$ & $3.4 \pm 0.5$ & $2.6 \pm 0.8$ & $2.9 \pm 0.6$ \\
\hline $\mathrm{TG}, \mathrm{mmol} / \mathrm{l}$ & $1.2 \pm 0.3$ & $1.4 \pm 0.5$ & $1.5 \pm 0.6$ & $1.5 \pm 0.4$ \\
\hline IL-6, pg/ml & $1.5 \pm 1.0$ & $1.2 \pm 1.1$ & $2.0 \pm 1.2$ & $2.0 \pm 1.1$ \\
\hline hs-CRP, mg/l & $3.7 \pm 0.9$ & $3.7 \pm 1.2$ & $3.9 \pm 0.7$ & $3.4 \pm 1.2$ \\
\hline First phase IS, pmol/l & $21 \pm 16$ & $32 \pm 15$ & $22 \pm 6$ & $30 \pm 11$ \\
\hline Late phase IS, pmol/l & $60 \pm 52$ & $51 \pm 25$ & $89 \pm 67$ & $76 \pm 40$ \\
\hline Total IS, pmol/l & $52 \pm 44$ & $45 \pm 21$ & $73 \pm 50$ & $62 \pm 29$ \\
\hline $\mathrm{M}, \mathrm{mg} / \mathrm{kg} / \mathrm{min}$ & $6.6 \pm 1.6$ & $5.3 \pm 2.1$ & $7.5 \pm 2.0$ & $6.7 \pm 1.2$ \\
\hline $\mathrm{M} / \mathrm{I}$ & $11 \pm 5.9$ & $8.9 \pm 6.3$ & $11 \pm 9.8$ & $7.9 \pm 4.8$ \\
\hline
\end{tabular}

IS = Insulin secretion; $\mathrm{M}$ = glucose metabolized (calculated with the clamp technique); $\mathrm{M} / \mathrm{I}=$ glucose metabolized/insulin concentration.

tions. Determinations were performed with commercially available equipment (Ortho-Clinical Diagnostics) with an intra- and inter-assay coefficient of variation of $<3 \%$. Insulin was measured by immunoradiometric assay (CIS Bio International, Gif sur Yvette, Cedex, France) with an intra- and inter-assay coefficient of variation of 3.8 and $8.0 \%$, respectively. ELISA was used to measure IL-6 concentration (Bender MedSystems, Burlingame, CA, USA) with an intra- and inter-assay coefficient of variation of 4.9 and $6.0 \%$, respectively. hs-CRP was measured by immunonephelometry (BN-II, Siemens, Marburg, Germany) with an intra- and inter-assay coefficient of variation of $<10 \%$. LDL-C was estimated using the Friedewald formula (LDL-C $=$ TC - HDL-C - TG / 5).

At the end of the present study, sample size was recalculated using the formula for clinical trials [13] with a $95 \%$ confidence level, a statistical power of $80 \%$, and a standard deviation (SD) of $6.0 \mathrm{pmol} / \mathrm{l}$ with an expected difference of $8.0 \mathrm{pmol} / \mathrm{l}$ for the first phase of insulin secretion. This resulted in a total of at least 6 individuals for each group, including an expected loss of $20 \%$. Values are presented as mean \pm SD. Betweengroup differences were analyzed by Mann-Whitney U test. Wilcoxon test was used for differences before and after the intervention in the same group.

The study was approved by the ethics committee of the participating hospital and fulfilled all requirements for research involving human subjects. All participants provided written informed consent.

\section{Results}

All 14 subjects who were eligible after screening completed 3 months of intervention. There were no significant differences in ages between the placebo and the ASU group (35.4 \pm 3.8 vs. $35.4 \pm 4.3$ years, $p=0.795$ ). There were no significant differences at baseline in clinical and laboratory measurements between groups (table 1). There were no significant differences between groups before and after placebo or ASU application in hs-CRP, IL-6, insulin secretion, and insulin sensitivity (table 1).

During the study, only 3 patients reported esophageal regurgitation symptoms (2 from the ASU group and 1 from the placebo group ( $p=0.350)$ ). No patients were excluded at the end of the study. 
Martínez-Abundis et al.: Effect of Avocado Soybean Unsaponifiables on Insulin Secretion and Insulin Sensitivity in Patients with Obesity

\section{Discussion}

To the best of our knowledge, the present study is the first randomized controlled clinical trial evaluating the effect of ASU on insulin secretion and insulin sensitivity in patients with obesity.

Obesity is the most common metabolic disease and is frequently associated with insulin resistance and defective insulin secretion due to a low-grade chronic inflammatory state as indicated by increased plasma concentrations of IL-6, CRP and others [13-16]. Adipose tissue secretes 15-35\% of circulating IL-6 [17], which decreases insulin signaling by reducing expression of insulin receptor throughout the process of inducing transcription of suppressor of cytokine signaling (SOCS) 3 proteins. In addition, IL-6 controls the expression of CRP in the liver $[18,19]$. Elevated CRP also stimulates endothelial production of E-selectin, intracellular cell adhesion molecule-1 (ICAM-1), and vascular cell adhesion molecule-1 (VCAM-1), which are important mediators of endothelial dysfunction [20,21]. Both IL- 6 and CRP have been associated with the risk of developing type 2 diabetes [22, 23]. A significant inhibition of different inflammatory cytokines (IL-1 $\beta$, IL-6, IL-8) in chondrocyte cultures after ASU administration has been reported [24]. Furthermore, other investigators reported a reduction of TNF- $\alpha$ [25]. These inflammatory molecules have all been implicated in the risk for developing type 2 diabetes mellitus and cardiovascular disease.

We evaluate IL-6 and hs-CRP as inflammatory molecules strongly linked to impaired insulin secretion and insulin sensitivity. However, in our study insulin secretion and sensitivity were not improved. IL- 6 and hs-CRP concentrations were not decreased after ASU administration. No changes were observed in the expression of CRP, probably because expression of this inflammatory marker depends on IL-6 stimulus. Although there are reports of clinical improvement at the same dose in patients with osteoarthritis (OA), these reports do not mention reduction in inflammatory molecules in humans [10]. Furthermore, our study group reported a significant increase in insulin secretion despite not having decreased concentrations of IL-6 after diacerein administration [26]. Likewise, another study reported an increase in insulin sensitivity without having observed changes in CRP after inhibition of cyclooxygenase-2 with celecoxib [27].

Another possible explanation is that the low-grade inflammatory behavior that is widespread in obesity may have a negative influence. This type of inflammatory behavior is chronic and generalized and different from that in OA where the inflammatory process is localized and more intense. It is possible that the production of IL- 6 in adipose tissue could not be effectively neutralized by ASU because a low concentration of IL- 6 is produced by adipose tissue.

These findings may be due to the highly selected population and the small number of patients included, because the statistical power was maintained after recalculating the sample size with the study values only in the first phase of insulin secretion. However, there are reports with a similar sample size with significant changes in these variables. In addition, we cannot exclude the fact that these variables may be modified by a longer intervention time.

Similar to other publications [28], no important adverse events were reported in this study after ASU administration. The main side effect reported was esophageal regurgitation, which decreased with the ingestion of the capsule with the meal.

In conclusion, although no changes were observed in insulin secretion and insulin sensitivity in patients with obesity, our study provides insight into anti-inflammatory drugs with different mechanisms of action in low-grade inflammatory diseases. 
Martínez-Abundis et al.: Effect of Avocado Soybean Unsaponifiables on Insulin Secretion and Insulin Sensitivity in Patients with Obesity

\section{Acknowledgments}

We thank Sharon Morey, Executive Editor, Scientific Communications, for English editorial assistance.

\section{Disclosure Statement}

No conflict of interest is reported with regard to this manuscript. The authors declare no competing interests with the mentioned pharmaceutical company.

\section{References}

1 Greenberg AS, Obin MS: Obesity and the role of adipose tissue in inflammation and metabolism. Am J Clin Nutr 2006;83:461s-465s.

-2 Caballero AE: Endothelial dysfunction in obesity and insulin resistance: a road to diabetes and heart disease. Obes Res 2003;11:1278-1289.

-3 Khaodhiar L, Ling PRL, Blackburn GL, Bistrian BR: Serum levels of interleukin-6 and C-reactive protein correlate with body mass index across the broad range of obesity. JPEN J Parenter Enteral Nutr 2004;28 $410-415$.

4 Festa A, D’Agostino R Jr, Williams K, Karter AJ, Mayer-Davis EJ, Tracy RP, Haffner SM: The relation of body fat mass and distribution to markers of chronic inflammation. Int J Obes Metab Disord 2001;25:1407-1415.

-5 Maury E, Brichard SM: Adipokine dysregulation, adipose tissue inflammation and metabolic syndrome. Mol Cell Endocrinol 2010;314:1-16.

-6 Ferrannini E, Camastra S, Gastaldelli A, Sironi MA, Natali A, Muscelli E, Mingrone G, Mari A: Beta-cell function in obesity: effects of weight loss. Diabetes 2004;53(suppl 3):S26-S33.

7 Khan SE: The importance of B-cell failure in the development and progression of type 2 diabetes. J Clin Endocrinol Metab 2001;86:4047-4058.

8 Wellen KE, Hotamisligil GS: Inflammation, stress, and diabetes: J Clin Invest 2005;115:1111-1119.

-9 Yudkin JS, Stehouwer CDA, Emeis JJ, Coppack SW: C-reactive protein in healthy subjects: associations with obesity, insulin resistance, and endothelial dysfunction: a potential role for cytokines originating from adipose tissue? Arterioscler Thromb Vasc Biol 1999;19:972-978.

-10 Au RY, Al-Talib TK, Au AY, Phan PV, Frondoza CG: Avocado soybean unsaponifiables (ASU) suppress TNF- $\alpha$, IL-1 $\beta$, COX-2, iNOS gene expression, and prostaglandin $\mathrm{E}_{2}$ and nitric oxide production in articular chondrocytes and monocytes/macrophages. Osteoarthritis Cartilage 2007;15:1249-1255.

-11 Boileau C, Martel-Pelletier J, Caron J, Msika P, Guillou GB, Baudouin C, Pelletier JP: Protective effects of total fraction of avocado/soybean unsaponifiables on the structural changes in experimental dog osteoarthritis: inhibition of nitric oxide synthase and matrix metalloproteinase-13. Arthritis Res Ther 2009;11:1-9.

12 DeFronzo RA, Tobin JD, Andres R: Glucose clamp technique: a method for quantifying insulin secretion and resistance. Am J Physiol 1979;237:E214-223.

13 Jeyasselan L, Rao PSS: Methods of determining samples size in clinical trials. Indian Pediatr 1989;26:115121.

14 Bastard JP, Maachi M, Lagathu C, Kim MJ, Caron M, Vidal H, Capeau J, Feve B: Recent advances in the relationship between obesity, inflammation, and insulin resistance. Eur Cytokine Netw 2006;17:4-12.

15 Visser M, Bouter LM, McQuillan GM, Wener MH, Harris TB: Elevated C-reactive protein levels in overweight and obese adults. JAMA 1999;282:2131-2135.

16 Liu S, Tinker L, Song Y, Rifai N, Bonds DE, Cook NR, Heiss G, Howard BV, Hotamisligil GS, Hu FB, Kuller LH, Manson JE: A prospective study of inflammatory cytokines and diabetes mellitus in a multiethnic cohort of postmenopausal women. Arch Intern Med 2007;167:1676-1685.

17 Spranger J, Kroke A, Möhlig M, Hoffmann K, Bergmann M, Ristow M, Boeing H, Pfeiffer AFH: Inflammatory cytokines and the risk to develop type 2 diabetes. Results of the Prospective Population-Based European Prospective Investigation into Cancer and Nutrition (EPIC)-Potsdam Study. Diabetes 2003;52:812-817.

-18 Mohamed-Ali V, Goodrick S, Rawesh A, Katz DR, Miles JM, Yudkin JS, Klein S, Coppack SW: Subcutaneous adipose tissue releases interleukin-6, but not tumor necrosis factor- $\alpha$, in vivo. J Clin Endocrinol Metab 1997; 82:4196-4200.

19 Klover PJ, Clementi AH, Mooney RA: Interleukin-6 depletion selectively improves hepatic insulin action in obesity. Endocrinology 2005;146:3417-3427.

-20 Glund S, Krook A: Role of interleukin-6 signaling in glucose and lipid metabolism. Acta Physiol 2008;192: 37-48.

21 Bloomgarden ZA: Inflammation, atherosclerosis, and aspects of insulin action. Diabetes Care 2005;28:23122319.

22 Meigs JB, Hu FB, Rifai N, Manson JE: Biomarkers of endothelial dysfunction and risk of type 2 diabetes mellitus. JAMA 2004;291:1978-1986. 
Martínez-Abundis et al.: Effect of Avocado Soybean Unsaponifiables on Insulin Secretion and Insulin Sensitivity in Patients with Obesity

23 Hu FB, Meigs JB, Li TY, Rifai N, Manson JE: Inflammatory markers and risk of developing type 2 diabetes in women. Diabetes 2004;53:693-700.

24 Duncan BB, Schmidt MI, Pankow JS, Ballantyne CM, Couper D, Vigo A, Hoogeven R, Folsom AR, Heiss G: Lowgrade systemic inflammation and the development of type 2 diabetes. The Atherosclerosis Risk in Communities Study. Diabetes 2003;52:1799-1805.

-25 Henrotin YE, Labasse AH, Jaspar JM, De Groote DD, Zheng SX, Guillou GB, Reginster JYL: Effects of three avocado/soybean unsaponifiable mixtures on metalloproteinases, cytokines and prostaglandin $\mathrm{E}_{2}$ production by human articular chondrocytes. Clin Rheumatol 1998;17:31-39.

-26 Ramos-Zavala MG, González-Ortiz M, Martínez-Abundis E, Robles-Cervantes JA, González-López R, SantiagoHernández NJ: Effect of diacerein on insulin secretion and metabolic control in drug-naive patients with type 2 diabetes: a randomized clinical trial. Diabetes Care 2011;34:1591-1594.

27 González-Ortiz M, Pascoe-González S, Martínez-Abundis E, Hernández-Salazar E: Effect of celecoxib, a cyclooxygenase-2-specific inhibitor, on insulin sensitivity, C-reactive protein, homocysteine, and metabolic profile in overweight or obese subjects. Metab Syndr Relat Disord 2005;3:95-101.

28 Ernst E: Avocado-soybean unsaponifiables (ASU) for osteoarthritis - a systematic review. Clin Rheumatol 2003;22:285-288. 